\title{
Resolving a location selection problem by means of an integrated AHP-RAFSI approach
}

\author{
Abdulaziz Alossta ${ }^{1}$, Omar Elmansouri ${ }^{2}$, Ibrahim badi ${ }^{3}$ \\ ${ }^{1}$ Civil engineering department, Faculty of Engineering, Misurata University, Libya, e-mail: \\ aalossta@eng.misuratau.edu.ly \\ ${ }^{2}$ Civil engineering department, Faculty of Engineering, Misurata University, Libya, e-mail: \\ omar.elmansouri@hotmail.com \\ ${ }^{3}$ Mechanical engineering department, Libyan Academy, Libya, e-mail: i.badi@lam.edu.ly
}

\section{Article Info}

Article history:

Received April 29, 2021

Revised June 8, 2021

Accepted June 9, 2021

\section{Keywords:}

Planning;

Location;

MCDM;

Site selection.

\begin{abstract}
The optimal Site selection operation is one of the most important challenges facing planners. Many location-allocation models have been developed based on multi-criteria decision making process. Recent methods take into account site, network, and user characteristics to determine the appropriate location. The development of optimum system has been a growing focus for most authorities across the world. It is generally thought that utlities allocation is the ultimate goal for service providers, which has been attributed to giving assistance in a time- and cost-efficient manner. In this paper, a multi-criteria decision making approach was implemented in two steps. Analytical hierarchy process (AHP) was adopted in the first step to determine the criteria weights. Results of AHP showed that response time had the highest weight among other criteria. Ranking of different alternatives was conducted in the second step using RAFSI model to choose the optimal location. Model ranking clearly indicated road-network as the best alternative to locate EMS centers.
\end{abstract}

Copyright (C) 2020 Regional Association for Security and crisis management and European centre for operational research. All rights reserved.

Corresponding Author:

Ibrahim Badi,

Mechanical engineering department, Libyan Academy, Libya.

Email: i.badi@lam.edu.ly

\section{Introduction}

Optimum distribution of services in urban areas is an essential concept of urban planning. Measuring service efficiency and adequacy is one of the important components of modern urban planning. Travel time and route distance are factors that could improve System performance and quality of service (Abd El Karim \& Awawdeh, 2020). The allocation of public utilities is a powerful approach to enhance social well-being through appropriate allocation of public facilities and resources (Abdelkarim, 2019). Although, urban planners are often deal with the problem of sites allocation, the methods used are still inconsistent and under study. Nevertheless, the location of the facilities affects the costs and the capability of the system to satisfy the demanded level of service, despite of the complicated analysis required to find the proper location (Rahman \& Smith, 2000). Location-allocation models have been used in planning for: siting warehouse stores, emergency stations, public facilities, and so forth (Ghosh \& Craig, 1984).

Emergency Medical Service (EMS) is very significant in society as it plays a vital role in saving thousands of lives and reducing the fatality rate (Aringhieri et al., 2017). EMS is one of the indispensable measures to enhance the safety of people and for sustaining human prosperity by minimizing the risk of accidental injuries or illness. Therefore, prehospital care could reduce mortality rate or injury severity. Mostly an ambulance location may influence a chance of rescue and patient survival. Thus, planners have realized how important the efficient EMS system is, and how EMS management is needed to save lives (Abdullah et al., 2018).

Almost all countries have Emergency Medical Services, even though the current systems in many developing countries are still confronted with numerous problems (Sariyer et al., 2017). In fact, the growing demand for transportation services; resulting in high accident rates; has not been accompanied by a similar development in the EMS systems (Elmansouri et al., 2020). It must be acknowledged that there has been an 
increase in demand for EMS services throughout the world; however, Libya suffers from the absence of such services. In 2021, the first EMS station was established to provide urgent treatment for injured users of the Libyan Coastal Road by calling an emergency number, 191.

Libyan population has been overgrowing in the past decade, when in fact the majority of citizens live along the coast where the most of major roads are located. Recently, planners have recognized the importance of EMS services and debates arose to determine the worthiness of placing the EMS stations within the urban areas or on highways. According to Traffic and Licensing Directorate, accidents in urban streets are less severe and deaths are unlikely to occur. Reports show that accidents inside cities do not exceed one-third of the total accidents in 2016-2017 (Elmansouri et al., 2020). Hence, Libyan government decided to construct seventy EMS centers along the coastal road, considering that most of the serious accidents happen on highways.

The matter of offering urgent medical assistant for emergency cases is not a priority for many developing countries' health systems (Razzak \& Kellermann, 2002). A reliable EMS system should be able to afford immediate emergency medical services to people who need it (Bhandari \& Yadav, 2020). The robust health system in the developed countries offers EMS that can be accessed by emergency dial number in the whole country (Bhandari \& Yadav, 2020). Kironji et.al conducted research on identifying barriers for out of hospital emergency care (OHEC) in developing countries. Kironji stated that 55\% of the articles he reviewed identified lack of transportation as a major issue for OHEC. He also mentioned that many patients are using taxies and animal drawn carts instead of ambulances. $61 \%$ of the reviewed articles showed lack of skilled personnel as a key barrier. Only $40 \%$ of health systems included in the review reported using an access phone number for emergency medical services (Kironji et al., 2018). Maintaining a good emergency care system in low-middle income countries can save $45 \%$ of deaths and $35 \%$ of permanent disabilities (Jamison et al., 2006). In low-middle income countries, approximately $80 \%$ of death due to severe injury occurs due to lack of quick medical assistant before the patient reach the hospital (Mock et al., 1998). About 60\% of the population in low-middle income countries live far than $8 \mathrm{~km}$ away from nearest hospital which results in a delay in helping an injures person (Forster et al., 2009).

The main objective of the paper is to find the optimal EMS sites that give the least response time. The methods used vary and mainly relate to the decision-making variables that are taken into consideration. Multi-criteria decision making (MCDM) will be used in the case of allocation emergency centers in Libya.

\section{Literature review}

There is a wide literature on site allocation modeling. Generally, all methods address the problem of service distribution to meet the ever-increasing demand, and satisfy the needs. The challenge for authorities is where to locate services and how many units are expected at the time. Several studies had been done over the past decades focused on making decision on the location of facilities. The most used models can be categorized into three types: static and deterministic models, probabilistic models, and dynamic models (Aringhieri et al., 2017). Multi-criteria decision making has been widely studied in recent years, where both criteria and alternatives vary when solving dynamic problems (Campanella \& Ribeiro, 2011).

Many researches use MCDM methods to determine the appropriate site selection. Popovic et al. (2019) tried to build a model for choosing a hotel location based on WS PLP method, however, the study was limited to a small number of criteria. Ren et al. (2019) used Grey decision making process to create a model of allocating electric vehicle charging stations. Abdel-Basset et al. (2021) combined AHP and PROMETHEE to select the optimal offshore wind power station location. The methodology was validated by an Egyptian case study. Rezaeisabzevar et al. (2020) used AHP and ANP to allocate landfill site. The study suggested that GIS has to be used as helpful tool when dealing with large and complicated data. In addition, experts' subjectivity and human judgement are shortcomings that reduce decision uncertainty in most studies.

Regarding the EMS, researches developed approaches to deal with the issue of not covering all demand points at certain times. Gendreau et al. (1997) introduced the double standard model (DSM) using the multiple coverage approach. Gendreau assumed that demand points are covered by more than one ambulance by maximizing the demand covered by at least two vehicles. Further improvement was introduced to the DMS by Schmid \& Doerner (2010) which assumed that certain number of residents can be sufficiently covered by one single ambulance. Probabilistic models were developed to overcome the weakness on deterministic models by taking into account that any ambulance could be busy when it is called (Toregas et al., 1971). Daskin introduced the Maximum Expected Coverage Location Problem (MEXCLP) assuming that all units are available at all times by considering each ambulance as independent and has the same probability of being busy. 


\section{Methodology}

MCDM is an approach for finding the optimal alternative from all the feasible alternatives according to some criteria or attributes (Badi \& Kridish, 2020; Pamučar et al., 2018; Stevic et al., 2017). In recent years, there has been an increase in interest in studies in multi-criteria decision-making problems. These decisions are complex in nature as a result of the lack of information on the problem, the often different nature of the criteria and the difficulty of determining the relevance of a criteria to another. In the area of logistics and transportation, many applications have emerged (Blagojević et al., 2020; Vesković et al., 2018). To identify the most important factors that affecting the site selection for emergency medical services, a two-step multi criteria model including a case study were conducted in this paper. The first step includes the definition of the influencing criteria on selecting the the best location. This step was done by the Analytical Heirarchy Process (AHP). The second step was the ranking of the alternatives which was done using RAFSI model. The multi criteria decision making techniques are very appropriate for such complicated problems. These problems require dealing with more than one criterion in order to solve them and reach an appropriate decision regarding them (Radović et al., 2018). Several methods have recently been developed that can solve these complex problems (Badi \& Ballem, 2018; Badi \& Pamucar, 2020; Eshtaiwi et al., 2018; Pamučar et al., 2018). The method used in this research is a compined AHP-RAFSI methods.

\subsection{Analytic Hierarchy Process}

Analytical hierarchy process is a popular MCDM method, and has been used more than any other MCDM methods (Badi et al., 2021). It was established by Saaty to provide a compliant and simple way of analyzing complicated problems (Badi \& Abdulshahed, 2019). It makes comparasion between potential pairs to weight each factor and give a consistency ratio by breaking down a complex problem into hierarchy or levels. The AHP handles a tree structure in order to simplify complex problems into unsophisticated and easily examined sub problems. The process can be distinguished in four main steps:

- $\quad$ Creating a tree structure, which consists of one goal, the criteria, and alternative solutions.

- $\quad$ Evaluating alternatives with respect to every criterion.

- Weighting factor Calculation using pairwise comparisons with subjective calculation.

- Synthesis of the outcomes of steps 2 and 3 in order to calculate the overall evaluation of alternatives in relation to the achievement degree of each goal.

The AHP is a multi-criteria decision-making tool that utilizes feedback from a well designed questionnaire. The approach evaluates the relative weights of factors based on pairwise comparisons in order to set priorities and arrive at best decision. The AHP Matrix is constructed using the comparisons and priorities are calculated using formula (1).

$$
A W=\lambda_{\max } w
$$

where $\mathrm{A}$ is the comparison matrix, $\lambda \max$ is the principal eigenvalue and $\mathrm{W}$ is the priority vector. The AHP model gives feedback to the decision maker on the consistency of the entered judgments through the measurement of consistency ratio (CR) by using formulas (2) and (3).

$$
\begin{aligned}
& C R=\frac{C I}{R I} \\
& C I=\frac{\lambda_{\text {max }^{-n}}}{n-1}
\end{aligned}
$$

Where CI is the consistency index, $\mathrm{n}$ is the dimension of the comparison matrix, $\lambda \max$ is the principal eigenvalue and RI is the ratio index. Table 1 shows the Random Consistency Index (RI) values versus dimension of the matrix (n). The matrix is considered consistent when $\mathrm{RI}<0.1$ while the matrix is considered inconsistent when RI>0.1. In case of inconsistent matrix, adjustment on the comparisons is preferred to reduce inconsistency (Stanković et al., 2019). Sub-priorities are summed if available in order to obtain alternative preferences and make decision based upon ranking.

Table 1. Random Consistency Index (RI)

\begin{tabular}{cccccccccc}
\hline $\mathrm{n}$ & 1 & 2 & 3 & 4 & 5 & 6 & 7 & 8 & 9 \\
\hline $\mathrm{RI}$ & 0 & 0 & 0.58 & 0.90 & 1.12 & 1.24 & 1.32 & 1.41 & 1.45 \\
\hline
\end{tabular}




\subsection{RAFSI method}

RAFSI method is one of the newest MCDM methods developed by Žižovi'c et al. (Žižović et al., 2020). For $m$ alternatives $A 1, A 2, \ldots$. An which have different weights $w j$, where $j=1,2, \ldots, n$, the initial decision matrix can be written as follows (Žižović et al., 2020):

$$
\mathrm{N}=\left[\begin{array}{ccccc}
\mathrm{n}_{11} & \mathrm{n}_{12} & \ldots \ldots . & \mathrm{n}_{1 \mathrm{n}} \\
\mathrm{n}_{21} & \mathrm{n}_{22} & \ldots \ldots . . & \mathrm{n}_{2 \mathrm{n}} \\
& & \ddots & & \\
\mathrm{n}_{\mathrm{m} 1} & \mathrm{n}_{\mathrm{m} 2} & \ldots \ldots \ldots & \mathrm{n}_{\mathrm{mn}}
\end{array}\right]
$$

The criteria can be of maximizing type ( $\max$ ) or minimizing type (min). Using such data and applying the model $\mathrm{R}$ based on the following steps:

Step 1: Define ideal and anti-ideal values. For each criterion $C_{j}(j=1,2, \ldots, n)$ the decision-maker defines two values $a_{I_{j}}$ and $a_{N_{j}}$, where $a_{I_{j}}$ represents ideal value of criterion $C_{j}$, while $a_{N_{j}}$ represents anti-ideal value of criterion $C_{j}$.

Step 2: Mapping of elements of initial decision matrix into criteria intervals. Based on the defined ideal and anti-ideal values, functions $f_{A_{i}}\left(C_{j}\right)$ are defined, which map the criterion intervals from the aggregated initial decision matrix $(\mathrm{N})$ to the criterion interval $\left[n_{1}, n_{b}\right]$. Criterion functions are defined for each criterion from the set $C_{j}(j=1,2, \ldots, n)$.

$$
f_{A_{i}}\left(C_{j}\right)=\frac{n_{b}-n_{1}}{n_{I_{j}}-n_{N_{j}}} n_{i j}+\frac{n_{I_{j}} \cdot n_{1}-n_{N_{j}} \cdot n_{b}}{n_{I_{j}}-n_{N_{j}}}
$$

where $n_{b}$ and $n_{1}$ represent the ratio that shows how much the ideal value is better than the anti-ideal value, while $n_{i j}$ denotes the value of the $\mathrm{i}$-th alternative for the $\mathrm{j}$-th criterion from the initial decision matrix.

It is suggested that the ideal value is at least six times better than the anti-ideal (barely acceptable value), or $n_{1}=1$ and $n_{b}=6$. However, the DM can use the other preferred values, for example $n_{1}=1$ and $n_{b}=9$. In this way, the standardized decision matrix $S=\left[s_{i j}\right]_{m \times n}(i=1,2, \ldots, m, j=1,2, \ldots, n)$ is obtained in which all elements of the matrix are mapped into the interval $\left[n_{1}, n_{b}\right]$.

Step 3: For the minimum and maximum sequence of elements, $\mathrm{n} 1$ and $\mathrm{n} 2 \mathrm{k}$, the arithmetic and harmonic means are determined using the expressions (2) and (3).

$$
\begin{aligned}
& A=\frac{n_{1}+n_{2 k}}{2} \\
& H=\frac{2}{\frac{1}{n_{1}}+\frac{1}{n_{2 k}}}
\end{aligned}
$$

Step 4: Form normalized decision matrix $S=\left[\hat{s}_{i j}\right]_{m \times n}(i=1,2, \ldots, m, j=1,2, \ldots, n)$. Using expressions (4) and (5), elements of matrix $S$ are normalized, and transferred into the interval $[0,1]$ :

a) for the criteria $\mathrm{C}_{\mathrm{j}}(j=1,2, \ldots, n)$ max type:

$$
\hat{s}_{i j}=\frac{s_{i j}}{2 A}
$$

b) for the criteria $\mathrm{C}_{\mathrm{j}}(j=1,2, \ldots, n)$ min type:

$$
\hat{s}_{i j}=\frac{H}{2 s_{i j}}
$$

In this way, a new normalized decision matrix is created, as shown below: 


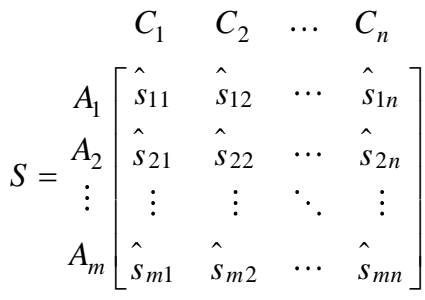

where $\hat{s}_{i j} \in[0,1]$ represents normalized elements of matrix $S$.

Step 5: Calculate the function parameters of the alternatives V(Ai). Expression (7) is used to calculate the criteria functions of the alternatives. Calculated V(Ai) is then used to rank the alternatives in descending order.

$$
V\left(A_{i}\right)=w_{1} \hat{s}_{i 1}+w_{2} \hat{s}_{i 2}+\ldots+w_{n} \hat{s}_{i n}
$$

\section{Results and discussion}

Libya suffers obvious lack of EMS services, and cities do not have adequate emergency health care facilities. Thus, infrastructure evolution must be made to establish new emergency centers and improve services. Efforts have to be done on scientific bases aiming to benefit and serve a wider cross sectio of society, and conveniently allocating sites on the right places.

In this work, we follow the approach used by Abdullah et al. (2018), which used four criteria as follows: response time $(\mathrm{C} 1)$, demand $(\mathrm{C} 2)$, coverage area $(\mathrm{C} 3)$, and ambulance workload $(\mathrm{C} 4)$. The alternatives of EMS sites are as follows: road network (A1), petrol stations (A2), parking lot (A3), clinics (A4), and coastal road (A5). The first stage is to determine the criteria weights. Group of experts have been invited to participate in the determination of the importance of each criterion for the evaluation of site locations. Table 2 shows the value of criteria weights and CR of each criterion.

Table 2. Criteria weights

\begin{tabular}{llc}
\hline CR & Sub-criteria & Weight \\
\hline \multirow{2}{*}{0.03} & Response time & 0.516 \\
& Demand & 0.241 \\
& Coverage area & 0.139 \\
& Ambulance workload & 0.103 \\
\hline
\end{tabular}

The previous table shows that the first criterion weights more than the others, given that EMS services are necessary in order to save lives and reduce severity of injuries. Moreover, showing up on time reduces the time and effort needed for treatment or recovery. All of that cannot be achieved if an ambulane arrival belated. Unfortunately, significant proportion of accidents in Libya is severe and requires urgent treatment; however, late arrival stands in the way of medical staff in hospitals where patients are mostly in a dangerous situation.

After the criteria weights were calculated, the alternatives are ranked using the RAFSI method. The initial decision matrix was prepared.

$$
\mathrm{N}=\left[\begin{array}{cccc}
90 & 80 & 80 & 65 \\
60 & 85 & 95 & 80 \\
70 & 80 & 85 & 85 \\
80 & 85 & 80 & 85 \\
75 & 80 & 75 & 70
\end{array}\right]
$$

RAFSI method can be implemented following the steps below.

Step 1: The definition of ideal and anti-ideal values of the criteria has been set by DMs.

$\mathrm{a}_{\mathrm{I}_{\mathrm{j}}}=[10,100,100,100]$

$\mathrm{a}_{\mathrm{N}_{\mathrm{j}}}=[100,10,10,10]$ 
Step 2: The criteria interval now can be formed as follows:

(a) For criteria with maximization objective

$\mathrm{C}_{2} \in[10,100] ; \mathrm{C}_{3} \in[10,100] ; \mathrm{C}_{4} \in[10,100]$

(b) For criteria with minimization objective

$\mathrm{C}_{1} \in[10,100]$

Step 3: Calculating the arithmetic and harmonic means of minimum and maximum elements $\mathrm{n}_{1}=1$ and $\mathrm{n}_{2 \mathrm{k}}=$ 5.

Step 4: The elements of matrix S are now normalized and transformed. New matrix is developed as follows:

$$
\widehat{\mathrm{S}}=\left[\begin{array}{llll}
0.58 & 0.69 & 0.31 & 0.43 \\
0.30 & 0.72 & 0.20 & 0.31 \\
0.36 & 0.69 & 0.28 & 0.28 \\
0.44 & 0.72 & 0.31 & 0.28 \\
0.39 & 0.69 & 0.35 & 0.39
\end{array}\right]
$$

Step 5: Table 3 shows the criteria functions $V\left(A_{i}\right)$ of the alternatives. These values are used to rank the alternatives.

Table 3. Ranking of the studied ports

\begin{tabular}{lrr}
\hline Alternative & $\mathrm{V}\left(\mathrm{A}_{\mathrm{i}}\right)$ & Rank \\
\hline A1 & 0.5320 & $\mathbf{1}$ \\
$\mathrm{A} 2$ & 0.3701 & $\mathbf{5}$ \\
$\mathrm{A} 3$ & 0.3981 & $\mathbf{4}$ \\
A4 & 0.4546 & $\mathbf{2}$ \\
A5 & 0.4393 & $\mathbf{3}$ \\
\hline
\end{tabular}

Although the majority of severe and fatal accidents occur on the coastal highway, the results of the model show that road network is the best alternative, followed by public clinics. This can be linked to the distribution of medical centers and hospitals within the urban areas; and so on an ambulance can travel from EMS center to sites and then hospital easily with the least response time. On the contrary, the second ranked alternative is clinics which can be a good choice; however, the estimated response time will be much longer considering the predicted length of the journey.

\section{Conclusion}

Emergency medical service is indispensable to a community in saving lives, improving safety, and reducing mortality. The quality of service provided always depends on the time taken by an ambulance to be at the scene. Locating EMS centers is one of the issues that challenge planners. The ever-growing population accompanied by a high increase of crashes has made the local authorities pay more attention and take serious actions.

Libyan government plans to establish new EMS stations. The planning requires a complicated process to choose the most strategic location for emergency stations. In this research, five alternatives are studied to choose the most suitable location for deploying ambulances using two of the MCDM methods. Alternatives were evaluated taking into account each evaluation criteria. The study concluded that the road network represents the best location for deploying ambulances. The suggested site provides direct and easy access to the traffic and reduces response time. The application of the proposed alternative remains open for further research with different methods of evaluating alternatives. Future studies might address more detailed criteria such as accident severity, congestion, and travel time.

\section{References}

Abd El Karim, A., \& Awawdeh, M. M. (2020). Integrating GIS Accessibility and Location-Allocation Models with Multicriteria Decision Analysis for Evaluating Quality of Life in Buraidah City, KSA. Sustainability, 12(4), 1412. 
Abdel-Basset, M., Gamal, A., Chakrabortty, R. K., \& Ryan, M. (2021). A new hybrid multi-criteria decisionmaking approach for location selection of sustainable offshore wind energy stations: A case study. Journal of Cleaner Production, 280, 124462.

Abdelkarim, A. (2019). Integration of Location-Allocation and Accessibility Models in GIS to Improve Urban Planning for Health Services in Al-Madinah Al-Munawwarah, Saudi Arabia. Journal of Geographic Information System, 11(06), 633.

Abdullah, L., Adawiyah, C., \& Kamal, C. (2018). A decision making method based on interval type-2 fuzzy sets: an approach for ambulance location preference. Applied computing and informatics, 14(1), 65-72.

Aringhieri, R., Bruni, M. E., Khodaparasti, S., \& van Essen, J. T. (2017). Emergency medical services and beyond: Addressing new challenges through a wide literature review. Computers \& Operations Research, 78, 349-368.

Badi, I., \& Abdulshahed, A. (2019). Ranking the Libyan airlines by using full consistency method (FUCOM) and analytical hierarchy process (AHP). Operational Research in Engineering Sciences: Theory and Applications, 2(1), 1-14.

Badi, I., \& Ballem, M. (2018). Supplier selection using the rough BWM-MAIRCA model: A case study in pharmaceutical supplying in Libya. Decision Making: Applications in Management and Engineering, 1(2), 16-33.

Badi, I., \& Kridish, M. (2020). Landfill site selection using a novel FUCOM-CODAS model: A case study in Libya. Scientific African, 9, e00537.

Badi, I., \& Pamucar, D. (2020). Supplier selection for steelmaking company by using combined GreyMARCOS methods. Decision Making: Applications in Management and Engineering, 3(2), 37-48.

Badi, I., Pamucar, D., Gigović, L., \& Tatomirović, S. (2021). Optimal site selection for sitting a solar park using a novel GIS-SWA'TEL model: A case study in Libya. International Journal of Green Energy, 18(4), 336-350.

Bhandari, D., \& Yadav, N. K. (2020). Developing an integrated emergency medical services in a low-income country like Nepal: a concept paper. International journal of emergency medicine, 13(1), 1-5.

Blagojević, A., Vesković, S., Kasalica, S., Gojić, A., \& Allamani, A. (2020). The application of the fuzzy AHP and DEA for measuring the efficiency of freight transport railway undertakings. Operational Research in Engineering Sciences: Theory and Applications, 3(2), 1-23.

Campanella, G., \& Ribeiro, R. A. (2011). A framework for dynamic multiple-criteria decision making. Decision Support Systems, 52(1), 52-60.

Elmansouri, O., Almhroog, A., \& Badi, I. (2020). Urban transportation in Libya: An overview. Transportation Research Interdisciplinary Perspectives, 8, 100161.

Eshtaiwi, M., Badi, I., Abdulshahed, A., \& Erkan, T. E. (2018). Determination of key performance indicators for measuring airport success: A case study in Libya. Journal of Air Transport Management, 68, 28-34.

Forster, G., Simfukwe, V., \& Barber, C. (2009). Use of intermediate modes of transport for patient transport: a literature review contrasted with the findings of the Transaid Bicycle Ambulance Project in Eastern Zambia. Publ Transaid LondonUnited Kingd.

Gendreau, M., Laporte, G., \& Semet, F. (1997). Solving an ambulance location model by tabu search. Location science, 5(2), 75-88.

Ghosh, A., \& Craig, C. S. (1984). A location allocation model for facility planning in a competitive environment. Geographical analysis, 16(1), 39-51.

Jamison, D. T., Breman, J. G., Measham, A. R., Alleyne, G., Claeson, M., Evans, D. B., . . Musgrove, P. (2006). Disease control priorities in developing countries: The World Bank.

Kironji, A. G., Hodkinson, P., De Ramirez, S. S., Anest, T., Wallis, L., Razzak, J., . . Hansoti, B. (2018). Identifying barriers for out of hospital emergency care in low and low-middle income countries: a systematic review. BMC health services research, 18(1), 1-20.

Mock, C. N., Jurkovich, G. J., Arreola-Risa, C., \& Maier, R. V. (1998). Trauma mortality patterns in three nations at different economic levels: implications for global trauma system development. Journal of Trauma and Acute Care Surgery, 44(5), 804-814.

Pamučar, D., Badi, I., Sanja, K., \& Obradović, R. (2018). A novel approach for the selection of powergeneration technology using a linguistic neutrosophic CODAS method: A case study in Libya. Energies, 11(9), 2489.

Pamučar, D., Lukovac, V., Božanić, D., \& Komazec, N. (2018). Multi-criteria FUCOM-MAIRCA model for the evaluation of level crossings: case study in the Republic of Serbia. Operational Research in Engineering Sciences: Theory and Applications, 1(1), 108-129.

Popovic, G., Stanujkic, D., Brzakovic, M., \& Karabasevic, D. (2019). A multiple-criteria decision-making model for the selection of a hotel location. Land use policy, 84, 49-58. 
Radović, D., Stević, Ž., Pamučar, D., Zavadskas, E., Badi, I., Antuchevičiene, J., \& Turskis, Z. (2018). Measuring performance in transportation companies in developing countries: a novel rough ARAS model. Symmetry, 10(10), 434.

Rahman, S.-u., \& Smith, D. K. (2000). Use of location-allocation models in health service development planning in developing nations. European journal of operational research, 123(3), 437-452.

Razzak, J. A., \& Kellermann, A. L. (2002). Emergency medical care in developing countries: is it worthwhile? Bulletin of the World Health Organization, 80, 900-905.

Ren, X., Zhang, H., Hu, R., \& Qiu, Y. (2019). Location of electric vehicle charging stations: A perspective using the grey decision-making model. Energy, 173, 548-553.

Rezaeisabzevar, Y., Bazargan, A., \& Zohourian, B. (2020). Landfill site selection using multi criteria decision making: focus on influential factors for comparing locations. Journal of Environmental Sciences.

Sariyer, G., Ataman, M. G., Akay, S., Sofuoglu, T., \& Sofuoglu, Z. (2017). An analysis of Emergency Medical Services demand: Time of day, day of the week, and location in the city. Turkish journal of emergency medicine, 17(2), 42-47.

Schmid, V., \& Doerner, K. F. (2010). Ambulance location and relocation problems with time-dependent travel times. European journal of operational research, 207(3), 1293-1303.

Stanković, M., Gladović, P., \& Popović, V. (2019). Determining the importance of the criteria of traffic accessibility using fuzzy AHP and rough AHP method. Decision Making: Applications in Management and Engineering, 2(1), 86-104.

Stevic, Z., Badi, I., Tanackov, I., \& Milicic, G. (2017). Supplier selection in furniture production company using rough AHP and rough TOPSIS. Paper presented at the VI International Symposium of Transport and Communications-New Horizons.

Toregas, C., Swain, R., ReVelle, C., \& Bergman, L. (1971). The location of emergency service facilities. Operations research, 19(6), 1363-1373.

Vesković, S., Stević, Ž., Stojić, G., Vasiljević, M., \& Milinković, S. (2018). Evaluation of the railway management model by using a new integrated model DELPHI-SWARA-MABAC. Decision Making: Applications in Management and Engineering, 1(2), 34-50.

Žižović, M., Pamučar, D., Albijanić, M., Chatterjee, P., \& Pribićević, I. (2020). Eliminating Rank Reversal Problem Using a New Multi-Attribute Model_-The RAFSI Method. Mathematics, 8(6), 1015. 